\title{
CORPO E FESTA NA ANTIGUIDADE TARDIA: O CONVIVIUM NAS SATURNAIS, DE MACRÓBIO
}

\author{
BODY AND FEAST IN LATE ANTIQUITY: THE \\ CONVIVIUM IN SATURNALIA, BY MACROBIUS \\ Jenny Barros Andrade ${ }^{I}$
}

Resumo: O presente artigo propõe analisar a representação do convivium realizado pelo escritor e filósofo Macróbio. Para tal, utilizamos sua obra Saturnais, escrita no início do século V d.C, onde narra um banquete realizado em honra a Saturno, durante as festividades realizadas em culto ao deus. Dessa forma, pretendemos analisar as regras de conduta e valores que regulam o corpo dos convivas e o momento festivo. Por fim, buscamos questionar a visão tradicional do banquete na Antiguidade, que é regularmente retratado como um momento de ausência de normas. Palavras-chave: Antiguidade Tardia; banquete; corpo; Macróbio; Saturnais.

Abstract: This article proposes to analyze the representation of convivium, realized by writer and philosopher Macrobius. For that, we utilized your work Saturnalia, written in the first half of V century, and describe a banquet realized in honor of the Saturn, during the annual festivities for that deity. Thus we intend to analyze the rules of conduct and the values that regulate the guest's body and the festivities. Lastly, we search to question the traditional view about the banquet, which is regularly represented as moment of absence of norm.

Keywords: Late Antiquity; banquet; body; Macrobius; Saturnalia.

\section{Macróbio e seu contexto histórico}

Na passagem do século IV ao V, é possível perceber uma série de transformações originadas ainda no século III no período da Anarquia

\footnotetext{
${ }^{1}$ Graduanda em História na Universidade Federal do Espírito Santo
} 
Militar $^{2}$, iniciada com o fim da dinastia dos Severos (235), e que trouxe grande instabilidade ao Império devido à contínua sucessão de imperadores e de invasões estrangeiras. Durante muito tempo, a fase final do Império foi tratada nos termos de "crise" e "declínio" pelos historiadores. Em contraposição a uma historiografia que poderíamos qualificar como tradicional há os autores como Peter Brown e Henri-Iréneé Marrou que optam por adotar o termo "Antiguidade Tardia" para qualificar esse período de transformações tão intensas. O fim do Mundo Antigo não deve ser caracterizado como um período de declínio, "mas sim de surgimento de novas concepções religiosas e estéticas, de novas invenções técnicas artísticas que exercem uma inegável influência sobre as sociedades posteriores" (SILVA; MENDES, 2006:195).

Segundo Silva e Mendes (2006), como forma de restauração da ordem no Império, os imperadores do século IV precisaram lançar mão

${ }^{2}$ Segundo Ana Teresa Marques Gonçalves (2006:185-189), o período conhecido como Anarquia Militar é caracterizado pela sucessão rápida de imperadores pelas legiões militares estacionadas nas fronteiras, para substituir os governantes mortos nas batalhas. Além disso, esses imperadores não se mantinham no poder por muito tempo, pois eram mortos por invasores ou por tropas insatisfeitas com sua liderança, dificultando a escolha de sucessores. Fatores como as lutas civis, a instabilidade política e a dificuldade de organizar dinastias no poder, levou a uma crise política e econômica, presente tanto no Ocidente quanto no Oriente. Segundo a autora, o estudo desse período é dificultado pela ausência de fontes literárias, embora a numismática e a epigrafia tenham contribuído para a análise. Embora tenha se passado uma visão de uma crise longa que abrangeu todo o Império, novos estudos a partir das inscrições provam que a crise política foi de caráter curto e que não afetou todas as zonas do Império ao mesmo tempo ou com a mesma intensidade. Dessa forma, não se aceita mais a concepção de uma crise geral no Império, embora, o uso de expressões como "Anarquia Militar", "Crise do Terceiro século" e "período dos Imperadoressoldados" continua a ser usado por falta de um novo termo. 
de um discurso que enfatizava a sua divinização, ainda em vida, fato que caracteriza o período do Baixo Império, conhecido como Dominato. O papel do imperador nesse momento é o de restaurador, salvador, alguém que poderia reordenar o Estado romano que se encontrava em crise. Nesse momento emerge a Basiléia, a realeza sagrada que abrangia tudo o que cercava o imperador.

Como não verificamos a separação entre Estado, sociedade e religião nesse momento, é importante mencionar as mudanças ocorridas no âmbito religioso dentro do Império, num contexto em que estava inserido o autor a ser trabalhado aqui, Macróbio Ambrósio Teodósio. Segundo Antolín (2010, p. 5), Macróbio é testemunha das invasões germânicas e da expansão do cristianismo, sendo contemporâneo à derrota de Eugenio diante das legiões de Teodósio em 394 d.C, além do saque de Roma diante dos visigodos, que ocorreu em 410 d.C. O conflito produzido pela ascensão do cristianismo e pela perda de espaço do paganismo é patente nesse momento, sendo que o paganismo sofre bastante com o crescimento da intolerância cristã. É a partir do reinado de Teodósio I, em 379 d.C, que os pagãos e heréticos são privados de seus direitos civis (BROWN, 1972). Segundo Momigliano (1992), os sacrifícios pagãos já haviam sido proibidos por Constâncio II, sendo que tal medida foi reforçada logo após pelo fechamento dos templos pagãos e pela proibição de sacrifícios em locais públicos. Em 391 d.C, Teodósio proibiu até mesmo o culto pagão privado, com a consequente restrição dos privilégios dos sacerdotes pagãos. 
O que podemos pensar diante de tal situação é de um completo fim do paganismo e uma cristianização total da população, principalmente no que condiz aos círculos aristocráticos. É possível analisar, porém, através da leitura de outras obras, que esse processo se constitui de forma bem mais lenta pelo Império, e com muito mais ênfase no Oriente do que no Ocidente, localidade em que nosso autor se encontra. Há uma cristianização muito mais no perímetro urbano do que no rural, além de um lento processo de conversão da aristocracia do século IV (JONES, 1989:32). Pois isso é mais do que necessário considerar o lugar do cristianismo e do paganismo na aristocracia romana durante os séculos IV e V, principalmente o lugar da cultura clássica, tão presente na obra de Macróbio.

Dessa forma, no século V d.C, durante o governo do Imperador Honório, o escritor e filósofo Macróbio Ambrósio Teodósio redige sua obra literária Saturnais. No que concerne à identidade do nosso autor, há um debate enorme, principalmente em relação ao seu período de vida e à sua real identidade. Não há informações, por exemplo, sobre o local do nascimento do nosso autor, porém sabe-se que ele não é natural de Roma, mas sim de outra região do Império, como a África. Um dos nomes que assinam os manuscritos das Saturnais é Macróbio Ambrósio Teodósio, porém segundo alguns historiadores como Alan Cameron (2011: 233), nosso autor seria conhecido muito provavelmente somente pelo nome de Teodósio. Essa informação pode nos parecer insignificante, porém ela altera sua identidade e logicamente o contexto em torno dele. Se antes Macróbio muito provavelmente teria vivido durante o 
século IV, nascido por volta de 350-360, tendo escrito as Saturnais em 395, alguns autores aceitam uma datação mais tardia da vida de Macróbio, tendo o mesmo nascido no fim do século IV, e tendo escrito as $\mathrm{Sa}$ turnais somente em 430. Dessa forma, Macróbio teria vivido sob os governos de Teodósio e Honório (ANTOLÍN, 2006: 24).

\section{Macróbio e sua obra pedagógica: Saturnais}

A obra Saturnais é composta por um conjunto de sete livros, que chegou até nós de forma incompleta, sendo um compêndio de saberes que seriam necessários à formação de um membro da elite. É possível constatar o objetivo pedagógico do autor, ao criar uma obra de erudição ${ }^{3}$, abordando assuntos como astrologia, literatura, gramática, retórica, entre outros conhecimentos. Devido a isso, sua obra é considerada uma literatura de erudição. Macróbio deixa bastante claro que o seu objetivo é deixar para o seu filho, Eustácio, obras que possam contribuir para sua formação.

Por isso, não considero nada mais importante que tua educação, (...) tudo o que tenho me esforçado em escrever em diversas obras em língua grega e latina, tanto antes de você nascer como depois do seu nascimento, que tudo isso constitua para ti um ba-

\footnotetext{
${ }^{3}$ Macróbio, ainda no prefácio de sua obra, deixa claro seu intento em criar uma obra que abarcasse diversos assuntos, com o propósito de contribuir para a formação de seu filho, Eustácio. Segundo Zelia de Almeida Cardoso (2011: 187-188), a obra de Macróbio é classificada com uma obra de erudição. Tal gênero abarca textos de caráter científico, que abarca o conhecimento dos eruditos, sendo a poligrafia bastante presente nos textos romanos. Ela ressalta, porém, que os gêneros na Antiguidade estavam estritamente ligados, de forma que as obras de erudição devem fazer parte da literatura latina.
} 
gagem de sabedoria; e como se uma dispensa literária se tratasse, se alguma vez você precisar se lembrar de uma história que, escondido na massa de livros, passar despercebido por todos, para você será mais fácil encontrá-la e tomá-la dali. (MACROBIO, Saturnales, I § 2-3, tradução nossa ${ }^{4}$ ).

O banquete de Macróbio tem como pano de fundo as festividades em honra ao deus Saturno, onde os personagens serão responsáveis por dialogar e debater os assuntos descritos acima no decorrer da festa. O momento do banquete é também retratado na literatura através do gênero literário do simpósio, que foi desenvolvido por alguns autores gregos e romanos na Antiguidade. Podemos citar o Banquete de Xenofonte, do século V a.C, ou então a obra do grego Plutarco, Quaestione Convivales (Symposiaka). Tais escritos possuem como modelo o Banquete de Platão, apresentando elementos em comum com a obra que se tornou referência desse gênero.

É necessário salientar que esses comensais presentes no banquete de Macróbio, possuíam conhecimento suficiente devido à sua formação, pois eram personagens históricos da elite durante o século $\mathrm{IV}^{5}$. Seria

\footnotetext{
${ }^{4}$ As citações diretas das Saturnalia foram extraídas da edição espanhola da editora Gredos, publicada em 2011. Para facilitar a compreensão do leitor, realizamos a tradução do espanhol para o português em todas as demais citações ao longo do artigo.
}

${ }^{5}$ A escolha de seus personagens não pode ser entendida como algo simplesmente aleatório. Adotando a cronologia proposta por Cameron, os personagens que Macróbio cita no momento da escrita da Saturnais já estavam mortos. Segundo Bloch (1989: 222), nosso autor possuía o desejo de trazer a tona novamente o que ele define como "os últimos pagãos de Roma", já que Bloch é um dos defensores da ideia de um renascimento pagão no fim do século IV. Entre as discussões que envolvem Macróbio, há também as que questionam se 
necessário somente citar alguns desses convivas presentes na obra para perceber que a grande maioria possuía uma educação que bebia nos clássicos. Vetio Agorio Pretextato, por exemplo, foi procônsul da Ásia e Prefeito de Roma (367-368), era um membro da nobreza senatorial romana e um grande defensor do paganismo. Outro personagem que deve ser descrito aqui, é Virio Nicômaco Flaviano, que é o anfitrião do segundo banquete na obra. Assim como Pretextato, também possuiu várias magistraturas, como governador da Sicília (364-365), vicário da África (376-377), prefeito do pretório da Itália, e cônsul em 394. (ANTOLÍN, 2010: 24). . É considerado também como um baluarte do paganismo, onde deu seu apoio ao usurpador Eugênio, pois segundo Antolín (2010, p.30), Flaviano via nele a oportunidade de restaurar os cultos pagãos. E por fim, temos a figura de Quinto Aurélio Símaco, que ocupou os cargos de procônsul da África (373-374), prefeito de Roma (384-405) e cônsul em 391 d.C. Era um representante da aristocracia senatorial romana, importante orador, e defensor da tradição e da religião pagã. Em 394 d.C., o mesmo faz um célebre discurso onde pede ao imperador Valentiano, que fosse reposto ao Senado romano o altar da deusa Vitória. Segundo Antolín, Símaco foi o último grande orador romano da tradição clássica (ANTOLÍN, 2010: 25).

\section{O banquete romano: Convivium}

realmente ele seria um escritor pagão, pois em suas obras ele não ataca de forma alguma o cristianismo. (CAMERON, 2011: 255) 
O momento festivo deve ser compreendido como um momento de sociabilidade, de interação e de convívio entre os participantes. O banquete, em particular, ainda na Grécia era considerado um "ato carregado de forte conteúdo social e de grande poder de comunicação" (FLANDRIN; MONTANARI, 1998:108). Durante o convivium retratado na obra de Macróbio, é possível perceber que há uma preocupação com o comportamento do conviva, onde seu corpo é moldado por regras e normas que devem ser respeitadas no decorrer da festa. Segundo Flandrin e Montanari "são as regras que verdadeiramente definem a especificidade do banquete 'civilizado' (...), ou seja, as normas de comportamento que marcam as diferenças em toda sociedade (...)". Esses integrantes, a partir do momento em que abrem mão de sua autonomia fisiológica e se adéquam às regras que lhes são impostas, experimentam um processo de socialização. Através da educação e pela formação cultural que possuem, os convivas se portam de determinada forma no momento do banquete, permitindo que o ambiente da festa, permeado por regras, conduza o seu comer, beber, agir e falar. De acordo com Rodrigues "são as convenções sociais, como se sabe, que decidem o que é alimento e o que não é alimento, bem como quem pode comer o quê e quando" (1979: 65). Rodrigues ressalta que o comer e o beber não são atos realizados de qualquer maneira, já que há um modo próprio de efetuá-los, dependendo do ambiente no qual o indivíduo se encontra.

É necessário realizar, porém, uma distinção entre o banquete grego e o romano a fim de entendermos melhor as relações e os significados neles implicados, embora constatemos uma clara 
continuidade de tal prática na Grécia e em Roma (GARNSEY, 1999:131). Na Grécia, havia um festim denominado symposium que tinha lugar logo após as refeições. Na ocasião, os convivas, ligados por vínculos que não eram necessariamente de parentesco, mas de estilo de vida, de formação cultural, se reuniam para consumir o vinho misturado com água. No simpósio grego, os convidados também conversavam sobre diversos assuntos, cantavam e recitavam poemas, dentre outras atividades lúdicas (CERQUEIRA, 2005: 37). Esse momento de sociabilidade é interpretado pelos especialistas como uma importante manifestação de coesão social e de unidade cultural, sendo inclusive utilizado como critério para diferenciar o grego do bárbaro, razão pela qual os ritos e regras que cercavam a comensalidade podem ser tidos como um elemento constitutivo da própria identidade grega.

Em relação ao banquete romano, nós temos o convivium que significa literalmente "vivendo junto", um momento de festa e convívio com consumação de comida e bebida (DUNBABIN, 2003:4). Diferente do symposium grego, o banquete romano admitia a participação de mulheres devido à influência etrusca (STRONG. 2004:28). Para participar do convivium era necessária a utilização de trajes especiais, a synthesis e o pallium, que eram respectivamente uma túnica e um pequeno casaco. É possível perceber esse fato no primeiro livro das Saturnais, onde o anfitrião do primeiro dia de banquete, Vetio Pretextato, ressalta que nos dias destinado às saturnais, não é permitido a ninguém se ocupar com assuntos públicos e nem permanecer vestido com "a toga, com a trábea, com o manto militar ou com a pretexta."(Sat., I,6, § 2). As 
roupas aqui citadas são utilizadas principalmente por altos magistrados, ou no caso do manto militar, pelos generais, porém deveriam ser abandonadas no momento da festa.

Segundo FRANCO (2004: 43), o número de convidados também era previamente determinado e variava de três a nove convivas, como vemos em nossa fonte. $\mathrm{O}$ momento festivo ocorria no triclinium, um divã ocupado pelos participantes segundo sua proximidade com o anfitrião. Assim, o lugar do conviva no espaço físico do banquete, além dos mecanismos de distribuição dos alimentos, exprimia a hierarquia presente nesse momento festivo. Há uma relação de poder claramente exposta no banquete, afinal, a oferta de alimentos era permeada de valores e de símbolos, variando de acordo com quem oferecia o banquete: no caso de um patrono diante de seu cliente, ou seja, de cima pra baixo, a oferta deveria ser entendida como "uma condescendência generosa e preeminência social; de baixo pra cima, ela denotaria veneração e sujeição. No plano horizontal, ela significaria simplesmente a pertença comum a um grupo" (FLANDRIN; MONTANARI, 1998:109). De acordo com Strong (2004: 29), o convivium "era uma elegante cerimônia de civilidade, ocasião em que o homem privado saboreava suas realizações e em certa medida exibi-a a seus pares no cenário de sua casa e de sua família".

Dessa forma, na sociedade greco-romana as boas maneiras irão definir o homem instruído, aquele que seria apto a participar da mesa. Assim, tanto em Roma quanto na Grécia, o banquete era considerado um dos sinais distintivos de civilização, pois eram as regras existentes 
durante esse momento de convívio que definiam o caráter "civilizado" daqueles que dele participavam. Desse modo, o banquete poderia agregar e unir, mas também separar e até mesmo excluir um indivíduo que porventura não conhecesse as suas normas.

Segundo Carneiro (2010: 45), na Antiguidade clássica prevalece o ideal de moderação e temperança, tanto na cultura grega quanto na latina. Tais virtudes também estão presentes na discussão dos convivas dentro da obra, como um elemento essencial para o momento da festa. No sétimo livro das Saturnais, há uma discussão entre os personagens de Símaco e Eustácio, onde o primeiro questiona se a filosofia deve estar presente nos banquetes. Eustácio responde tal indagação reafirmando o respeito necessário para o debate da filosofia, porém faz a seguinte observação: "Mas se por isso será exilada dos simpósios, se afastarão também suas alunas, isto é, a honestidade e a moderação, e não menos a religiosidade junto com a sobriedade. Qual delas poderia dizer que é menos venerável?" (Sat., VII, $1, \S 5$, tradução nossa).

A temperança é uma das virtudes éticas de Aristóteles, onde cada uma delas se refere a das esferas da alma: "para a esfera apetitiva, a temperança; para a afetiva, a coragem; para a intelectiva, a prudência; e para equilibrar todas, a justiça" (CARNEIRO, 2010:69). O conceito de temperança ou moderação (Sophrosyne) governa os prazeres do corpo, mais precisamente os provenientes do paladar e do tato, pois os demais sentidos com a visão, a audição, e o olfato são a contemplação do belo, e não corre o risco da intemperança. Macróbio, no decorrer dos diálogos, irá ressaltar o perigo do vício e do descontrole dos prazeres. 
Mas, de fato, o prazer excessivo pelo gosto e pelo tato - duplo prazer, então - é, na opinião de homens sábios, o mais vil de todos, e aqueles, em especial, que se entregaram a esses prazeres, os gregos os denominaram, com os vocábulos que aludem ao grau extremo do vício, como akrateís ou akolástoi, e nós como incontinentes ou intemperantes. (Sat., II, 8, § 11-12)

A temperança é um ponto intermediário entre dois vícios: um causado pelo excesso e o outro pela carência. Segundo Carneiro (2010:71) "Os antigos viam na temperança uma equidistância tanto do excesso como da abstinência. $\mathrm{O}$ 'caminho do meio' era, nesse como em outros casos, o mais correto e virtuoso". Na obra de Macróbio, Vetio Pretextato, alerta exatamente para o perigo de ceder a algum dos vícios e não manter o equilíbrio necessário.

Posto que nas saturnais, o dia mais feliz, segundo o poeta de Verona, não devemos repudiar o prazer, como se fosse um inimigo, como fariam os estoicos, nem tampouco colocar o bem supremo no prazer, na maneira dos epicuristas, pensemos em uma alegria carente de lascívia(...). (Sat., II, $1, \S 8$ )

Uma das principais discussões envolvia a ingestão do vinho. $\mathrm{Na}$ Antiguidade, a forma como se realizava o consumo da bebida distinguia o indivíduo civilizado do bárbaro. $\mathrm{O}$ fato de se ter o cuidado com o uso do vinho, revela que isso porta um significado: de civilização, de distinção. Uma prática comum, era a mistura do vinho com a água para dosar a bebida realizada nas crateras, que são recipientes próprios para essa prática. 
Segundo o personagem Eustácio, quando se bebe com moderação, o indivíduo consegue se controlar e facilmente retomar às suas atividades diárias. Porém, se há a perda de controle, todos os afetos e segredos serão revelados devido à liberdade que o vinho lhe dá (Sat., II, $8, \S 6-7)$.

\footnotetext{
"Na verdade, aquele que desconhece os encantos e prazeres dos banquetes e que não têm a menor experiência deles, se por acaso sua própria vontade o leva, ou a casualidade o conduz, ou a necessidade o empurra a participar dos prazeres de tal natureza, é imediatamente seduzido e subjugado, e nem sua mente nem seu espírito se mantêm firmes. Há, portanto, que iniciar um combate e como se em um campo de batalha, lutar corpo a corpo com os prazeres e com esse desenfreio por vinho, a fim de se proteger contra eles; não com a fuga ou com a abstinência, mas com a força do caráter e com sangue frio, e conservar, com o uso moderado, a temperança e a moderação.” (Sat., II, 8, § 8-9)
}

Eustácio, na última passagem, alerta para a prudência durante o momento do banquete. É possível perceber que o homem não deve ser guiado pela sua própria vontade, pelos prazeres e por sua necessidade, mas deve combater tais vícios buscando a moderação e a temperança.

\section{Considerações finais}

Os convivas no diálogo se preocupavam com a temperança, uma virtude que deveria estar presente no momento do convivium. A transgressão dos códigos de conduta ali presentes traz sobre eles o caráter de intemperantes e até mesmo de bárbaros, podendo construir ou reforçar a identidade desse grupo. Através dos trechos aqui expostos, foi possível identificar regras que são citadas na obra e perceber que o ambiente da 
festa está permeado por normas que irão moldar o corpo desse comensal. Macróbio não representa as saturnais como um período de aniquilamento de uma ordem, mas uma festa que possui suas leis para o cumprimento do ritual.

\section{Referências Bibliográficas}

\section{Documentação Primária Impressa}

MACROBIO. Saturnales. Traducción de Fernando Navarro Antolín. Madrid: Gredos, 2010.

\section{Referências Complementares}

ABBAGnANO, N. Dicionário de filosofia. São Paulo: Mestre Jou, 1970.

AGNOLON, A. A Festa de Saturno: o Xênia e o Apoforeta de Marcial. 2013. Tese (Doutorado em Letras Clássicas) - Faculdade de Filosofia, Letras e Ciências Humanas, Universidade de São Paulo, São Paulo, 2013.

BLOCH, $\mathrm{H}$. El renascimiento del paganismo en occidente a fines del siglo IV. In: MOMIGLIANO, Arnaldo (Org.). El conflicto entre el paganismo y el cristianismo en el siglo IV. Madrid: Alianza Universidad, 1989. p. 207- 232.

BROWN, P. O fim do Mundo Clássico: De Marco Aurélio a Maomé. Lisboa: Editorial Verbo, 1972.

CAMERON, A. The Last Pagans of Rome. Oxford; New York: Oxford University Press, 2011. 
CARDOSO, Z. A. A literatura latina. São Paulo: WMF Martins Fontes, 2011.

CARNEIRO, H. Bebida, abstinência e temperança na história antiga e moderna. São Paulo: Editora Senac São Paulo, 2010.

CERQUEIRA, F. Música e gênero no Banquete: o registro da iconografia ática e dos textos antigos (sec. VI-V a.C). In: LESSA, Fabio Souza; BUSTAMANTE, Regina Maria. (Org.). Memória \& Festa. 1ed. Rio de Janeiro: Mauad, 2005, v. 1, p. 37-47.

DUNBABIN, K. The roman banquet: images of conviviality. Cambridge: Cambridge University Press, 2003.

FERNANDES, A. T. Ritualização da Comensalidade. Porto: Universidade do Porto. Faculdade de Letras, 1995. Separata da Revista da Faculdade de Letras. Sociologia, Porto, I Série, vol. 7, 1997.

FLANDRIN, J. L. MONTANARI, Massimo. História da alimentação. São Paulo: Estação Liberdade, 1998.

GARNSEY, P. Food and society in classical antiquity. New York: Cambridge University Press, 1999

GONÇALVES, A. T. M.. A Festa como Fronteira: Repensando o Ordenamento do Poder na Roma Imperial. In: XXV Simpósio Nacional de História da Anpuh, 2009, Fortaleza - CE. Anais do Simpósio Nacional de História. Fortaleza - CE: Ed. UFCE, 2009. v. 1. p. 1-15.

Os Severos e a Anarquia Militar. In: SILVA, G. V.; MENDES, M. M. (Orgs.). Repensando o Império Romano: Perspectiva Socioeconômica, Política e Cultural. Vitória: EDUFES, 2006. p.175-191.

GUARINELLO, N. L. Festa, Trabalho e Cotidiano. In: JANCSÓ, István; KANTOR, Íris (orgs.). Festa: Cultura \& Sociabilidade na América Portuguesa. São Paulo: Edusp, 2001. V.2, P.969-975. 
JONES, A. H. M. El trasfondo social de la lucha entre el paganism y el cristianismo. In: MOMIGLIANO, Arnaldo (Org.). El conflicto entre el paganismo y el cristianismo en el siglo IV. Madrid: Alianza Universidad, 1989. p. 31-52.

REMÓNDON, R. La crisis del Imperio Romano: de Marco Aurellio hasta Anastacio. Barcelona: Labor, 1967.

RODRIGUES, J. C. Tabu do corpo. Rio de Janeiro: Achiame, 1979.

SILVA, G. V.; MENDES, N. Diocleciano e Constantino: A construção do DOMINATO. IN: SILVA, G. V.; MENDES, N. (Org.). Repensando o Império Romano: perspectiva socioeconômica, política e cultura. Vitória: EDUFES, 2006.

STRONG, R. Banquete: uma história ilustrada dos costumes e da fartura à mesa. Rio de Janeiro: Jorge Zahar, 2004.

VALERI, V. Festa. In: ROMANO, R.(Dir.) Enciclopédia Einaudi. Lisboa: Imprensa Nacional Casa da Moeda, 1972, p. 402-415.v. 30

VEYNE, P. Humanitas: Romanos e não-romanos. In: GIARDINA, Andréa. (Ed.). O Homem Romano. Tradução de Maria Jorge Vilar de Figueiredo. Lisboa: Estampa, 1992, p. 296.

Recebido em: 10/06/2015

Aceito em: 10/04/2016 
